\title{
Fidelity to individual components of a standardized labor induction protocol and association with improved obstetric outcomes: secondary analysis of a randomized controlled trial
}

\section{Rebecca Feldman Hamm ( $\nabla$ feldmara@gmail.com )}

University of Pennsylvania School of Medicine https://orcid.org/0000-0002-2587-2054

\section{Rinad S Beidas}

University of Pennsylvania Department of Psychology

\section{Sindhu K. Srinivas}

University of Pennsylvania Perelman School of Medicine

Lisa D. Levine

University of Pennsylvania Perelman School of Medicine

\section{Research}

Keywords: fidelity, protocol components, labor induction, standardization, simplification, effectiveness outcomes, cesarean rate, maternal morbidity, neonatal morbidity

Posted Date: January 6th, 2020

DOl: https://doi.org/10.21203/rs.2.20098/v1

License: (c) (1) This work is licensed under a Creative Commons Attribution 4.0 International License.

Read Full License 


\section{Abstract}

\section{Background}

Standardized labor induction protocols improve obstetric outcomes. However, these protocols are complex. The Consolidated Framework for Implementation Research describes intervention components as "core" and "adaptable periphery." We aimed to identify core components by investigating the individual components of an evidence-based protocol most associated with effectiveness. We planned to utilize this information to simplify our protocol prior to multi-site implementation.

\section{Methods}

This is a secondary analysis of an RCT comparing time to delivery among four labor induction methods. All patients enrolled in the trial had their labor managed with a multidisciplinary-developed, evidencebased labor induction protocol. For each patient's induction, we assessed fidelity to 7 components of the protocol. Primary effectiveness outcomes included cesarean delivery, maternal morbidity, and neonatal morbidity. Bivariate analyses assessed association of each component with each primary effectiveness outcome. Multivariable logistic regression determined independent predictors of each outcome while controlling for demographic and clinical factors known to be related to our outcomes.

Results

The 491 patients enrolled in the RCT were included in this analysis. While multiple components were associated with each outcome in bivariate analysis, few were found to be independent predictors of effectiveness in multivariable analysis. For cesarean delivery, only one component "for women in active labor, all cervical exams were performed $\leq 2.5$ hours apart" was an independent predictor. For maternal morbidity, only one "if an intracervical Foley catheter was utilized for cervical ripening, it was removed within 12 hours of placement" remained significant. For neonatal morbidity, two components "all cervical exams performed in latent labor were performed $\leq 4.5$ hours apart" and "for women in active labor, all cervical exams were performed $\leq 2.5$ hours apart" remained independent predictors. Of the independent predictors of effectiveness, most reflected the overarching concept of "frequent exams in labor will allow for more frequent intervention when no change is made".

\section{Conclusions}

This study demonstrates a novel strategy to identify which components of an evidence-based intervention should be "core" and which are "adaptable periphery"; this provides valuable information when designing for dissemination and implementation. With an understanding of the relationship between fidelity to individual protocol components and effectiveness, we can systematically simplify interventions prior to large-scale implementation, a potential strategy to increase implementation success. These data will be used to streamline our protocol to best target cesarean rate and maternal/neonatal morbidity prior to a planned type I hybrid effectiveness-implementation trial. 


\section{Contributions To The Literature:}

- Standardized labor induction protocols improve obstetric outcomes. However, these protocols are complex and difficult to implement.

- To best prepare our protocol for implementation success, we identified the individual components of a labor induction protocol most associated with effectiveness.

- Understanding the relationship between fidelity to individual intervention components and improved effectiveness is a novel strategy to determine core components in an evidence-based fashion, with the potential to increase large-scale implementation success.

- Our data will be used to streamline our protocol to best target cesarean rate and maternal/neonatal morbidity prior to a planned type I hybrid effectiveness-implementation trial.

\section{Background:}

The Consolidated Framework for Implementation Research (CFIR) describes complex interventions as having "core components" and "adaptable periphery" [1]. Core components are referred to as those essential items that cannot be altered without harming the integrity of the intervention, while the adaptable periphery is thought to be alterable to a specific clinical context [2,3]. Damschroder et al points out how few papers describing implementations clearly delineate where interventions component fall within this framework, and how utilization of this terms in implementation science literature would ease widespread replication [1, 4]. Yet, little work has been done on how best to differentiate between core components and adaptable periphery. This study details a novel strategy for determining core intervention components through the example of an evidence-based practice within obstetrics.

In obstetrics, labor induction makes up $20 \%$ of all deliveries in the United States (US), accounting for approximately 900,000 US women annually [5]. Labor induction is defined as the stimulation of labor contractions during pregnancy before labor begins spontaneously, with the goal of achieving a vaginal delivery. As the cervix needs to soften, thin, and open to prepare for delivery, cervical ripening methods, such as medications or devices, are utilized. Throughout the course of an induction, additional interventions known to be effective in spontaneous labor management [6-10], such as artificial rupture of the amniotic sac and utilization of oxytocin, may be incorporated. Components of decision-making during labor induction, such as frequency of cervical exams, when and if to perform artificial membrane rupture, use of oxytocin and intrauterine pressure catheters (a device used to measure contraction strength), as well as thresholds for cesarean section, are highly variable across and within centers [1112].

The utilization of protocols to standardize care has been shown to decrease adverse outcomes in various medical fields, including obstetrics [13-20]. The American College of Obstetricians and Gynecologists (ACOG) has led a national effort to establish protocols and standardize labor and delivery management [16]. Our group has retrospectively evaluated our hypothesis that standardization of labor induction can improve overall obstetric outcomes [21-22]. Cesarean delivery rate and maternal/neonatal morbidity 
were compared between women in a randomized trial of cervical ripening agents who were undergoing labor induction with a standardized protocol versus an observational cohort of women being induced at the same time, with labor management at the discretion of the provider. The standardized labor induction protocol was approved by a multidisciplinary institutional obstetrical committee prior to its initiation and included recommendations for frequent cervical exams and interventions such as oxytocin and amniotomy at particular time points. We found that utilization of a standardized labor induction protocol led to a $70 \%$ reduction in neonatal morbidity overall (RR: $0.31,95 \% \mathrm{Cl}: 0.13-0.70$ ), as well as a $35 \%$ reduction in primary cesarean delivery rate specifically for Black women, (RR 0.64 95\% Cl: 0.45-0.92), thereby eliminating a racial disparity in cesarean rate.

However, like most interventions, protocols regarding labor, such as the standardized labor induction protocol used in our preliminary work, are complex and multi-pronged. We believe that simplifying our protocol would lead to more successful implementation and dissemination [23-24]. Thus, we aimed to determine core components of our effective labor induction protocol that improve three important obstetric outcomes: cesarean delivery rate, maternal morbidity, and neonatal morbidity. Our overall goal was to streamline the standardization of labor induction to a more parsimonious protocol for a planned, future type I hybrid effectiveness-implementation trial [25].

\section{Methods:}

We performed a secondary analysis of a randomized clinical trial comparing time to delivery among four different induction methods (misoprostol alone, cervical Foley alone, misoprostol/cervical Foley concurrently, cervical Foley/oxytocin concurrently) [26]. This study was performed at the Hospital of the University of Pennsylvania from May 2013 to June 2015. This study was approved by the institutional review board at the University of Pennsylvania and all women provided written consent before participation in this study.

Women were included in this study if they had labor induced for any indication and met the following inclusion criteria: full term ( $\geq 37$ weeks), $\geq 18$ years of age in cephalic presentation, with amniotic membranes not ruptured, and a cervical exam that required a ripening agent to begin labor. Women were excluded from the study if they had a prior cesarean delivery, had a multiple gestation (e.g. twins, triplets), a contraindication to vaginal delivery, major fetal anomaly, did not speak English, or had a maternal condition requiring special management in labor such as HIV or eclampsia [26].

Women enrolled in this study were recommended to have their induction and labor managed with a standardized protocol specific to the cervical ripening method. The protocol was derived by two of the investigators (LDL, SKS) and approved by an institutional Obstetrical committee prior to initiation of the randomized trial. It was modeled after prior studies that utilized an active management protocol [6-10]. The protocol was used for induction management, as well as latent (defined as the stage of labor prior to $6 \mathrm{~cm}$ dilation) and active labor (defined as the stage of labor at $\geq 6 \mathrm{~cm}$ ). The cervical ripening method was the only thing that could differ among women. For the purpose of the current study, the protocol was 
divided into seven specific recommendations that we could determine, based on review of the Electronic Health Record (EHR), whether the provider was or was not compliant with that protocol component for a given patient. These were referred to as fidelity measures. Four of these measures were recommendations for management within latent labor and three were within active labor. In addition, the investigators came to a consensus that these 7 fidelity measures cluster into 3 themes that reflect why we believed they may work to improve outcomes (Table 1). These themes included: (1) "do not continue futile procedures", (2) "frequent exams will allow for more frequent intervention when no change is made", and (3) "intervene when cervical change is not made".

Table 1

Standardized Labor Induction Protocol Fidelity Measures:

\section{Standardized Labor Induction Protocol Fidelity Measures}

Measure Protocol Recommendation

Theme \#1: Do not continue futile procedures.
\#1 If a foley balloon is utilized, it is to
(Latent)
be removed 12 hours after
placement or when falls out.
\#2 If misoprostol is utilized, it should
(Latent) not be continued beyond 6 doses or
24 hours of use.
If a foley balloon was utilized, did it fall out/was it removed by 12.5 hours after placement?
If misoprostol was used, was it used for less than
24 hours and less than or equal to 6 doses?

Compliance Determination

Theme \#2: Frequent exams will allow for more frequent intervention when no change is made.

$\begin{array}{lll}\begin{array}{l}\text { \#3 } \\ \text { (Latent) }\end{array} & \begin{array}{l}\text { Exams should be performed every } \\ 2-4 \text { hours in latent labor. }\end{array} & \begin{array}{l}\text { Were all exams in latent labor performed less than } \\ \text { or equal to } 4.5 \text { hours apart? }\end{array} \\ \begin{array}{lll}\text { \#4 } & \text { Exams should be performed every } & \text { Were all exams in active labor performed less than } \\ \text { (Active) } & 1-2 \mathrm{hrs} \text { in active phase. } & \text { or equal to } 2.5 \text { hours apart? }\end{array}\end{array}$

Theme \#3: Intervention when cervical change is not made.

\begin{tabular}{|c|c|c|}
\hline $\begin{array}{l}\# 5 \\
\text { (Latent) }\end{array}$ & $\begin{array}{l}\text { If patient is } \geq 4 \mathrm{~cm} \text { dilated and has } \\
\text { intact membranes, perform } \\
\text { amniotomy. }\end{array}$ & $\begin{array}{l}\text { If the patient reached } 4 \mathrm{~cm} \text {, was the patient } \\
\text { already ruptured or amniotomy performed at that } \\
\text { exam? }\end{array}$ \\
\hline $\begin{array}{l}\# 6 \\
\text { (Active) }\end{array}$ & $\begin{array}{l}\text { If patient has same exam } 2 \text { hours } \\
\text { apart in active labor, and is already } \\
\text { ruptured, oxytocin should be } \\
\text { started. }\end{array}$ & $\begin{array}{l}\text { If active labor was reached and the patient was } \\
\text { already ruptured with } 2 \text { exams at the same } \\
\text { dilation } 2 \text { hours apart, was oxytocin } \\
\text { started/running? }\end{array}$ \\
\hline $\begin{array}{l}\# 7 \\
\text { (Active) }\end{array}$ & $\begin{array}{l}\text { If patient has same exam } 2 \text { hours } \\
\text { apart in active labor, and is already } \\
\text { on oxytocin/ruptured, place } \\
\text { intrauterine pressure catheter. }\end{array}$ & $\begin{array}{l}\text { If active labor was reached and the patient was } \\
\text { already ruptured and on oxytocin with } 2 \text { exams at } \\
\text { the same dilation } 2 \text { hours apart, was an } \\
\text { intrauterine pressure catheter placed? }\end{array}$ \\
\hline
\end{tabular}

To determine fidelity to the protocol, for every woman enrolled, the labor process was examined through the EHR for compliance with each of the seven recommendations. Delivery, maternal, and neonatal 
outcomes were recorded. Primary effectiveness outcomes were: (1) cesarean delivery (2) composite maternal morbidity (defined as any of the following that occurred during labor, delivery, or in the 4 weeks postpartum: blood transfusion, endometritis, wound separation/infection, venous thromboembolism, hysterectomy, intensive care unit admission, or death) and (3) composite neonatal morbidity (defined as any of the following that occurred prior to neonatal discharge: neonatal resuscitation requiring supplemental oxygen outside of the delivery room or culture proven/presumed neonatal sepsis).

Bivariate comparisons of each of the seven fidelity measures with each of the three primary effectiveness outcomes were performed with Fisher exact tests and chi square tests, where appropriate. Bivariate analysis was considered to be significant if $p<0.20$, as we were willing to accept a $20 \%$ chance of type I error to keep a component in our protocol. Multivariable logistic regression was used to assess for independent predictors of each outcome while controlling for key demographic and clinical factors that impact cesarean and morbidity such as age, body mass index (BMI), and parity. Demographic and clinical characteristics associated on bivariate tests $(p<0.20)$ with the outcome of interest were evaluated as potential covariates if they had biologic plausibility to be confounders. These were placed into each model with the individual fidelity measures found to be associated with that effectiveness outcome. Backwards stepwise elimination of covariates (with $p$-value $>0.20$ for removal) was performed for each regression model to determine which covariates and fidelity measures to retain in the final models. The final multivariable models include all variables with a $p<0.05$. Statistical analyses were performed with Stata 15 (StataCorp, College Station, TX). This study was performed with a fixed sample size determined by those who enrolled in the original study.

\section{Results:}

Based on the sample size of the parent, randomized trial, 491 women were included in this analysis. Demographic and clinical characteristics are detailed in Table 2. Included women were of median age 27, $77.6 \%$ identified as Black, and $93.7 \%$ were overweight or obese at delivery by BMI. Of our sample, $27.7 \%$ $(n=136)$ underwent cesarean delivery, $7.3 \%(n=36)$ met criteria for maternal morbidity, and $3.1 \%(n=15)$ met criteria for neonatal morbidity. 
Table 2

Demographic and Clinical Information:

Demographic

Maternal Age

Race

Black/African American

Caucasian

Asian

Other/Unknown

BMI at delivery

$<25.0$ (Normal weight)

25.0-29.9 (Overweight)

30.0-34.9 (Obese Class 1)

35.0-39.9 (Obese Class 2)

$\geq 40.0$ (Obese Class 3)

Insurance

Private

Public/Uninsured

Nulliparous

Gestational age at induction*

Diabetes

Gestational diabetes

Pre-gestational

Chronic hypertension

Pregnancy Related Hypertension

GHTN/Mild PEC

Severe/Superimposed PEC

Indication for induction

Later term/post-term

Maternal §

Fetal II

Elective/Other ${ }^{9}$
$N(\%)$

$27[22-32]$

$381(77.6)$

$76(15.5)$

$11(2.2)$

$23(4.7)$
$29(6.3)$

$123(26.9)$

$110(24.0)$

$105(22.9)$

$91(20.0)$

$165(33.6)$

$326(66.4)$

$290(59.1)$

39 [38-40]

$33(6.7)$

$11(2.2)$

$40(8.1)$

114 (23.2)

$50(10.2)$

$64(13.0)$

$148(30.1)$

$225(45.8)$

$54(11.0)$

* Median (Inter-quartile range); § Examples include: chronic hypertension, gestational hypertension, preeclampsia, diabetes, renal disease, history of venous thromboembolism, cardiac disease or other chronic medical condition where induction was recommended; "Examples include: Oligohydramnios, intrauterine growth restriction, abnormality on fetal testing; " Examples of "other" include: history of an intrauterine fetal demise, vaginal bleeding at term, cholestasis 


\section{Demographic}

Bishop score at induction *

Cervical dilation at induction *

${ }^{\star}$ Median (Inter-quartile range); § Examples include: chronic hypertension, gestational hypertension, preeclampsia, diabetes, renal disease, history of venous thromboembolism, cardiac disease or other chronic medical condition where induction was recommended; "Examples include: Oligohydramnios, intrauterine growth restriction, abnormality on fetal testing; " Examples of "other" include: history of an intrauterine fetal demise, vaginal bleeding at term, cholestasis

Table 3 shows bivariate comparisons between each of the seven fidelity measures and each of the three effectiveness outcomes. For cesarean delivery, five of the seven fidelity measures were found to be significantly associated with effectiveness: (1) "if an intracervical Foley catheter was utilized for cervical ripening, it was removed within 12 hours of placement" (29.3\% cesarean rate in compliant inductions vs. $50.0 \%$ in non-compliant inductions, $p=0.13$ ), (2) "all cervical exams performed in latent labor were performed $\leq 4.5$ hours apart" ( $21.0 \%$ vs. $34.3 \%, p=0.001)$, (3) "if misoprostol was utilized, it was not continued beyond 6 doses or 24 hours of use" (20.3\% vs. $48.8 \%, p<0.001)$, (4) "for women in active labor, all cervical exams were performed $\leq 2.5$ hours apart" ( $14.8 \%$ vs. $34.0 \%, p<0.001)$, and (5) "if patient has the same exam 2 hours apart in active labor, and is already on oxytocin with a ruptured amniotic sac, an intrauterine pressure catheter should be placed" $(19.2 \%$ vs. $40.5 \%, p=0.002)$. 
Table 3

Bivariate Comparisons Among Fidelity Measures and Effectiveness Outcomes:

$\begin{array}{llllllll}\text { Fidelity Measure } & \mathrm{N}(\%) & \text { Cesarean } & \mathrm{p} & \text { Maternal } & \mathrm{p} & \text { Neonatal } & \mathrm{p} \\ & & \text { Delivery } & \text { value } & \text { Morbidity } & \text { value } & \text { Morbidity } & \text { value }\end{array}$

\section{LATENT LABOR MEASURES}

1. If a foley balloon is utilized, it is to be removed 12 hours after placement or when falls out.

Theme \#1; $\mathrm{n}=363$ foley balloons placed
0.13
0.07
0.64

Yes, Compliant with

Protocol

No, Noncompliant

with Protocol

$\begin{array}{ll}351 & 103 \\ (96.7 \%) & (29.3 \%)\end{array}$

12

$(3.3 \%)$
$6(50.0 \%)$
$13(3.7 \%)$

$0(0)$

2. Exams should be performed every $2-4$ hours in latent labor.

Theme \#2; $\mathrm{n}=491$ (all patients)

0.001
$3(25.0 \%)$

$27(7.7 \%)$

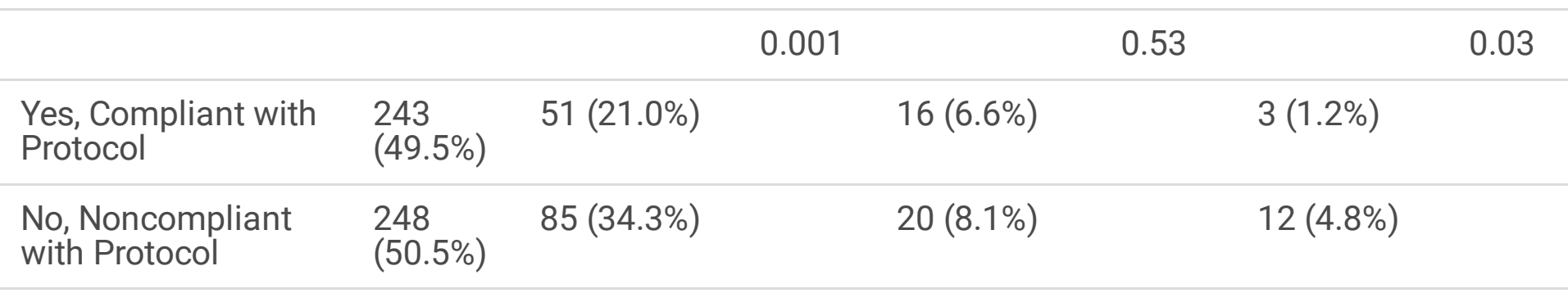

3. If misoprostol is utilized, it should not be continued beyond 6 doses or 24 hours of use.

Theme $\# 1 ; n=238$ inductions with misoprostol used

$\begin{array}{lll}< & 0.005 & 0.28\end{array}$

$\begin{array}{lllll}\begin{array}{l}\text { Yes, Compliant with } \\ \text { Protocol }\end{array} & \begin{array}{l}197 \\ (82.8 \%)\end{array} & 40(20.3 \%) & 7(3.6 \%) & 4(2.0 \%) \\ \begin{array}{l}\text { No, Noncompliant } \\ \text { with Protocol }\end{array} & \begin{array}{l}41 \\ (17.2 \%)\end{array} & 20(48.8 \%) & 6(14.6 \%) & 2(4.9 \%)\end{array}$

4. If patient is $\geq 4 \mathrm{~cm}$ dilated and has intact membranes, perform amniotomy.

Theme $\# 3 ; n=481$ (all patients reached $4 \mathrm{~cm}$, but 10 rupture dilations were unknown)

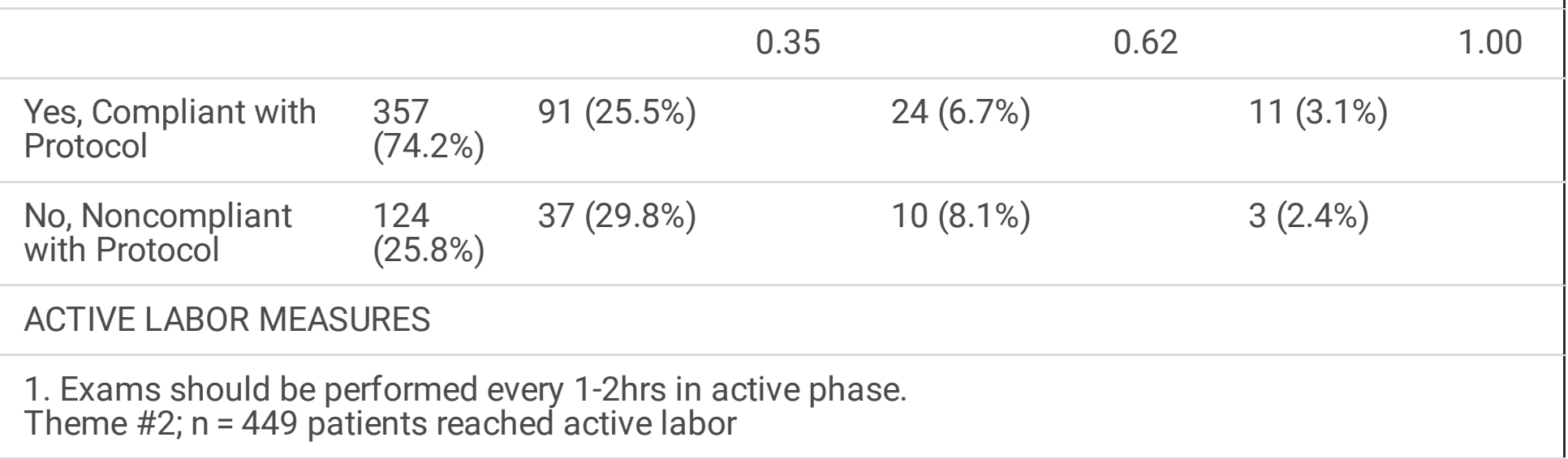




\begin{tabular}{|c|c|c|c|c|c|c|c|}
\hline Fidelity Measure & $\mathbf{N}(\%)$ & $\begin{array}{l}\text { Cesarean } \\
\text { Delivery }\end{array}$ & $\begin{array}{l}\mathbf{p} \\
\text { value }\end{array}$ & $\begin{array}{l}\text { Maternal } \\
\text { Morbidity }\end{array}$ & $\begin{array}{l}\mathrm{p} \\
\text { value }\end{array}$ & $\begin{array}{l}\text { Neonatal } \\
\text { Morbidity }\end{array}$ & $\begin{array}{l}\mathbf{p} \\
\text { value }\end{array}$ \\
\hline & & & $<0.001$ & & 0.58 & & 0.03 \\
\hline $\begin{array}{l}\text { Yes, Compliant with } \\
\text { Protocol }\end{array}$ & $\begin{array}{l}305 \\
(67.9 \%)\end{array}$ & 45 (14.8\%) & & $19(6.2 \%)$ & & $5(1.6 \%)$ & \\
\hline $\begin{array}{l}\text { No, Noncompliant } \\
\text { with Protocol }\end{array}$ & $\begin{array}{l}144 \\
(32.1 \%)\end{array}$ & 49 (34.0\%) & & $11(7.6 \%)$ & & 8 (5.6\%) & \\
\hline \multicolumn{8}{|c|}{$\begin{array}{l}\text { 2. If patient has same exam } 2 \text { hours apart in active labor, and is already ruptured, oxytocin should be } \\
\text { started. } \\
\text { Theme \#3; } n=449 \text { patients reached active labor }\end{array}$} \\
\hline & & & 1.00 & & 1.00 & & 1.00 \\
\hline $\begin{array}{l}\text { Yes, Compliant with } \\
\text { Protocol }\end{array}$ & $\begin{array}{l}356 \\
(98.1 \%)\end{array}$ & $88(24.7 \%)$ & & $27(7.6 \%)$ & & $13(3.7 \%)$ & \\
\hline $\begin{array}{l}\text { No, Noncompliant } \\
\text { with Protocol }\end{array}$ & $\begin{array}{l}7 \\
(1.9 \%)\end{array}$ & $1(14.3 \%)$ & & $0(0)$ & & $0(0)$ & \\
\hline \multicolumn{8}{|c|}{$\begin{array}{l}\text { 3. If patient has same exam } 2 \text { hours apart in active labor, and is already on oxytocin and ruptured, } \\
\text { place intrauterine pressure catheter. } \\
\text { Theme } \# 3 ; n=449 \text { patients reached active labor }\end{array}$} \\
\hline & & & 0.002 & & 0.30 & & 0.29 \\
\hline $\begin{array}{l}\text { Yes, Compliant with } \\
\text { Protocol }\end{array}$ & $\begin{array}{l}411 \\
(91.7 \%)\end{array}$ & 79 (19.2\%) & & $26(6.3 \%)$ & & 11 (2.7\%) & \\
\hline $\begin{array}{l}\text { No, Noncompliant } \\
\text { with Protocol }\end{array}$ & $\begin{array}{l}37 \\
(8.3 \%)\end{array}$ & $15(40.5 \%)$ & & $4(10.8 \%)$ & & $2(5.4 \%)$ & \\
\hline
\end{tabular}

For maternal morbidity, two measures were significantly associated with effectiveness: (1) "if an intracervical Foley catheter was utilized for cervical ripening, it was removed within 12 hours of placement" $(7.7 \%$ maternal morbidity rate in compliant inductions vs. $25.0 \%$ maternal morbidity in noncompliant inductions, $p=0.07$ ) and (2) "if misoprostol was utilized, it was not continued beyond 6 doses or 24 hours of use" ( $3.6 \%$ vs. $14.6 \%, p=0.005)$. Both of these measures fit under theme \#1, "do not continue futile procedures."

Finally, for neonatal morbidity, two different measures were significantly associated with effectiveness: (1) "all cervical exams performed in latent labor were performed $\leq 4.5$ hours apart" (1.2\% neonatal morbidity in compliant inductions vs. $4.8 \%$ in non-compliant inductions, $p=0.03$ ) and (2) "for women in active labor, all cervical exams were performed $\leq 2.5$ hours apart" (1.6\% vs. $5.6 \%, p=0.03)$. Both measures fit under theme \#2, "frequent exams will allow for more frequent intervention when no change is made." 
While multiple fidelity measures were associated with each outcome in bivariate analysis, few were found to be independent predictors of effectiveness outcomes in multivariable analysis when controlling for body mass index, parity, and race. For cesarean delivery, only (1) "for women in active labor, all cervical exams were performed $\leq 2.5$ hours apart" was an independent predictor. For maternal morbidity, (1) "if an intracervical Foley catheter was utilized for cervical ripening, it was removed within 12 hours of placement" remained significant. For neonatal morbidity (1) "all cervical exams performed in latent labor were performed $\leq 4.5$ hours apart" and (2) "for women in active labor, all cervical exams were performed $\leq 2.5$ hours apart" remained independent predictors. Of the independent predictors of effectiveness for all effectiveness outcomes, most reflected theme \#2, "frequent exams in labor will allow for more frequent intervention when no change is made."

\section{Discussion:}

This study presents a novel strategy to determine core intervention components in a standardized labor induction protocol and their association with critical obstetric effectiveness outcomes. In finding three of seven fidelity measures to be independently associated with cesarean delivery, maternal morbidity, or neonatal morbidity, we have the potential to streamline our labor induction protocol to focus on these components prior to large-scale implementation in a planned type I hybrid effectiveness-implementation trial.

The sharp increase in the US cesarean rate from 1996 through 2011 without a subsequent decrease in maternal or neonatal morbidity has raised significant concern that cesarean delivery is overused [27]. Statewide analyses have demonstrated that $15-40 \%$ of cesareans may be medically unnecessary [2829]. Large-scale work that effectively reduces the primary cesarean rate has thus far been limited.

Furthermore, maternal morbidity and mortality in the United States is highest among all developed nations [30]. In addition, racial disparities are present in most obstetric outcomes, with Black women at greater risk of perinatal morbidity than non-Black women [31-32]. Black women in the United States are twice as likely to experience a fetal mortality and nearly 4 times more likely to die themselves in and around pregnancy [33-34]. In addition, Black women have higher cesarean rates than non-Black women even when accounting for sociodemographic and clinical differences [35].

The utilization of protocols to standardize care has decreased adverse outcomes in various medical fields, including obstetrics [13-20]. This led us to study a novel means of reducing the primary cesarean rate: standardization of labor induction. Our prior work demonstrated that standardization of labor induction practices into a comprehensive protocol is associated with a reduction in the primary cesarean rate for Black women, as well as neonatal morbidity overall [21-22].

However, even if the labor induction protocol improves outcomes in a research setting, our intervention can only impact national health outcomes if patients and clinicians are willing to accept the protocol into routine care. Thus, we are planning a prospective, type I hybrid effectiveness-implementation trial [25] to evaluate the effectiveness of our standardized labor induction protocol, while simultaneously assessing 
implementation outcomes in order to best prepare our intervention for widespread, successful dissemination and implementation in the national arena.

Our data demonstrated that three of seven individual components of a standardized labor induction protocol were independently associated with effectiveness outcomes: cesarean delivery, maternal morbidity, or neonatal morbidity. Those components found to be important mainly fell under the theme of "frequent exams in labor will allow for more frequent intervention when no change is made." This finding reflects the idea that, with frequent exams, we can more quickly diagnose issues with labor progress. With timely diagnosis, we can more quickly intervene, and thus prevent lengthy and failed inductions, which may lead to cesarean, as well as morbidity for mother and baby. Thus, as we move forward with our planned prospective, type I hybrid trial, we will focus our intervention on this theme.

An additional strength of this study is its focus on health disparities, a field onto which implementation science has only recently focused its lens [36-37]. The concepts presented in this work may be transferable to other evidence-based practices designed to reduce such disparities.

This study has several limitations. First, while we were able to establish seven discrete fidelity measures that could be pulled from the medical record, there were several less concrete protocol components that were unable to be evaluated in this work. Second, several of the components were so well adhered to that it was difficult to see an association with effectiveness. If more inductions had been noncompliant with those components, an association with effectiveness may have been able to be established. Thus, it would be prudent to incorporate these highly adhered to components into the protocol for our planned trial, as they may still have an important impact on outcomes. Maternal and neonatal morbidity are also rare outcomes, at $7.3 \%$ and $3.1 \%$ respectively, limiting their evaluation, particularly within regression modeling, in our small sample size. Finally, this is a secondary analysis of a randomized trial performed at one, urban, academic site, limiting generalizability of these results to our planned multi-site implementation.

\section{Conclusions:}

While the study of fidelity to an intervention and its relationship to effectiveness is not a new concept, this study is unique in its overarching goal: to utilize data on fidelity to individual intervention components and their association with effectiveness as a means to systematically identify core components. This knowledge can be used to simplify a protocol prior to large-scale implementation. The concept of streamlining multi-component interventions in an evidence-based fashion could present a novel strategy for implementation acceptability, adoption, and penetration.

\section{Declarations}

Ethics approval and consent to participate: This study was approved by the institutional review board at the University of Pennsylvania and all women provided written consent before participation in this study. 
Consent for publication: NA

Availability of data and material: The datasets used and/or analyzed during the current study are available from the corresponding author on reasonable request.

Competing interests: The authors declare that they have no competing interests.

Funding: This study was funded in part by a career development award in Women's Reproductive Health Research: K12-HD001265-15 and a T32 Training Grant in Reproductive Epidemiology: T32-HD007440.

Authors' contributions: RH, LL, and SS conceived and designed this work. $\mathrm{RH}$ analyzed the data under the guidance of LL, SS, and RB. RH drafted the work, and it was substantially revised by LL, SS, and RB. All authors approved of the final version of this work and ensure its accuracy and integrity.

Acknowledgements: NA

\section{References}

1. Damschroder LJ, Hagedorn HJ. A guiding framework and approach for implementation research in substance use disorders treatment. Psychol Addict Behav. 2011;25(2):194-205.

2. Damschroder LJ, Aron DC, Keith RE, Kirsh SR, Alexander JA, Lowery JC. Fostering implementation of health services research findings into practice: a consolidated framework for advancing implementation science. Implement Sci. 2009;4:50.

3. Greenhalgh T, Robert G, Macfarlane F, Bate P, Kyriakidou O. Diffusion of innovations in service organizations: systematic review and recommendations. Milbank Q. 2004;82(4):581-629.

4. Michie S, Fixsen D, Grimshaw JM, Eccles MP. Specifying and reporting complex behaviour change interventions: the need for a scientific method. Implement Sci. 2009;4:40.

5. Center for Disease Control and Prevention. Recent declines in induction of labor. http://www.cdc.gov/nchs/data/databriefs/db155.htm. Accessed March 1, 2016.

6. O'Driscoll K, Foley M, MacDonald D. Active management of labor as an alternative to cesarean section for dystocia. Obstet Gynecol. 1984;63(4):485-490.

7. Lopez-Zeno JA, Peaceman AM, Adashek JA, Socol ML. A controlled trial of a program for the active management of labor. N Engl J Med. 1992;326(7):450-454.

8. Frigoletto FD, Jr., Lieberman E, Lang JM, et al. A clinical trial of active management of labor. N Engl J Med. 1995;333(12):745-750.

9. Peaceman AM, Socol ML. Active management of labor. Am J Obstet Gynecol. 1996;175(2):363-368.

10. Gerhardstein LP, Allswede MT, Sloan CT, Lorenz RP. Reduction in the rate of cesarean birth with active management of labor and intermediate-dose oxytocin. J Reprod Med. 1995;40(1):4-8.

11. Falciglia GH, Grobman WA, Murthy K. Variation in labor induction over the days of the week. Am J Perinatol. 2015;32(1):107-12. 
12. Glantz JC. Obstetric variation, intervention, and outcomes: doing more but accomplishing less. Birth. 2012;39(4):286-90.

13. Thuzar M, Malabu UH, Tisdell B, Sangla KS. Use of a standardised diabetic ketoacidosis management protocol improved clinical outcomes. Diabetes Res Clin Pract. 2014;104(1):e8-e11.

14. Committee Opinion No. 680: The Use and Development of Checklists in Obstetrics and Gynecology. Obstet Gynecol. 2016;128(5):e237-e240.

15. Pronovost $P$, Needham $D$, Berenholtz $S$, et al. An intervention to decrease catheter-related bloodstream infections in the ICU. N Engl J Med. 2006;355(26):2725-2732.

16. Committee Opinion No. 629: Clinical guidelines and standardization of practice to improve outcomes. Obstet Gynecol. 2015;125(4):1027-1029.

17. Kirkpatrick DH, Burkman RT. Does standardization of care through clinical guidelines improve outcomes and reduce medical liability? Obstet Gynecol. 2010;116(5):1022-1026.

18. Clark S, Belfort M, Saade G, et al. Implementation of a conservative checklist-based protocol for oxytocin administration: maternal and newborn outcomes. Am J Obstet Gynecol. 2007;197(5):026.

19. Clark SL, Belfort MA, Byrum SL, Meyers JA, Perlin JB. Improved outcomes, fewer cesarean deliveries, and reduced litigation: results of a new paradigm in patient safety. Am J Obstet Gynecol. 2008;199(2):12.

20. Hehir MP, Mackie A, Robson MS. Simplified and standardized intrapartum management can yield high rates of successful VBAC in spontaneous labor. J Matern Fetal Neonatal Med. 2017;30(12):1504-1508.

21. Levine LD, Downes KL, Hamm RF, Srinivas SK. Evaluating the impact of a standardized induction protocol to reduce adverse perinatal outcomes: a prospective cohort study. J Matern Fetal Neonatal Med. Epub ahead of print October 2019.

22. Hamm RF, Srinivas SK, Levine LD. A standardized labor induction protocol: impact on racial disparities in obstetric outcomes. AJOG MFM. November 2019, Under Review.

23. Frieden TR. Six components necessary for effective public health program implementation. Am J Public Health. 2014;104(1):17-22.

24. Sutcliffe K, Thomas J, Stokes G, Hinds K, Bangpan M. Intervention Component Analysis (ICA): a pragmatic approach for identifying the critical features of complex interventions. Syst Rev. 2015;4:140.

25. Landes SJ, Mcbain SA, Curran GM. An introduction to effectiveness-implementation hybrid designs. Psychiatry Res. 2019;280:112513.

26. Levine LD, Downes KL, Elovitz MA, Parry S, Sammel MD, Srinivas SK. Mechanical and Pharmacologic Methods of Labor Induction: A Randomized Controlled Trial. Obstet Gynecol. 2016;128(6):13571364.

27. Safe prevention of the primary cesarean delivery. Obstetric Care Consensus No. 1. American College of Obstetricians and Gynecologists. Obstet Gynecol 2014;123:693-711. 
28. Koroukian SM, Trisel B, Rimm AA. Estimating the proportion of unnecessary Cesarean sections in Ohio using birth certificate data. J Clin Epidemiol. 1998;51(12):1327-34.

29. Kabir AA, Steinmann WC, Myers L, et al. Unnecessary cesarean delivery in Louisiana: an analysis of birth certificate data. Am J Obstet Gynecol. 2004;190(1):10-9.

30. MacDorman MFDE, Cabral H, Morton C. Recent increases in the US maternal mortality rate: disentangling trends from measurement issues. Obstet Gynecol. 2016;128(3):447-5.

31. Creanga AA, Bateman BT, Kuklina EV, Callaghan WM. Racial and ethnic disparities in severe maternal morbidity: a multistate analysis, 2008-2010. Am J Obstet Gynecol. 2014;210(5):435.e1-8.

32. Hirshberg A, Srinivas SK. Epidemiology of maternal morbidity and mortality. Semin Perinatol. 2017;41(6):332-337.

33. ACOG Committee Opinion No. 649: Racial and Ethnic Disparities in Obstetrics and Gynecology. Obstet Gynecol. 2015;126(6):e130-4.

34. Moaddab A, Dildy GA, Brown HL, et al. Health Care Disparity and Pregnancy-Related Mortality in the United States, 2005-2014. Obstet Gynecol. 2018;131(4):707-712.

35. Yee LM, Costantine MM, Rice MM, et al. Racial and Ethnic Differences in Utilization of Labor Management Strategies Intended to Reduce Cesarean Delivery Rates. Obstet Gynecol. 2017;130(6):1285-1294.

36. Chinman M, Woodward EN, Curran GM, Hausmann LRM. Harnessing Implementation Science to Increase the Impact of Health Equity Research. Med Care. 2017;55 Suppl 9 Suppl 2:S16-S23.

37. Roberts MC, Mensah GA, Khoury MJ. Leveraging Implementation Science to Address Health Disparities in Genomic Medicine: Examples from the Field. Ethn Dis. 2019;29(Suppl 1):187-192.

\section{Supplementary Files}

This is a list of supplementary files associated with this preprint. Click to download.

- STROBEchecklistcohort.docx 